\title{
Lycopersicon esculentum lectin: an effective and versatile endothelial marker of normal and tumoral blood vessels in the central nervous system
}

\author{
S. Mazzetti, S. Frigerio, * M. Gelati, * A. Salmaggi, * L. Vitellaro-Zuccarello \\ Dipartimento di Scienze Biomolecolari e Biotecnologie, Università degli Studi di Milano; *Istituto \\ Nazionale Neurologico "Carlo Besta", Milan, Italy
}

(C)2004, European Journal of Histochemistry

The binding of Lycopersicon esculentum lectin (LEA) to the vascular endothelium was studied in the central nervous system of rat, mouse and guinea pig at different developmental ages, and in a gliosarcoma model. Our observations showed that LEA consistently stained the entire vascular tree in the spinal cord and in the brain of all animal species at all developmental ages investigated. In the tumor model, the staining of the vascular network was very reproducible, enabled an easy identification of vascular profiles and displayed a higher efficiency when compared to two other commonly used vascular marker (EHS laminin and PECAM-1). Moreover, our results showed that LEA staining was comparable in both vibratome and paraffin sections and could be easily combined with other markers in double labeling experiments.

These observations indicate that LEA staining may represent an effective and versatile endothelial marker for the study of the vasculature of the central nervous system in different animal species and experimental conditions.

Key words: Lycopersicon esculentum, lectin histochemistry, brain, spinal cord, blood vessels, gliosarcoma, glycocalyx

Correspondence: Laura Vitellaro-Zuccarello, Dipartimento di Scienze Biomolecolari e Biotecnologie, via Celoria 26, 20133 Milan, Italy.

Phone: international +39.02 .50314883 .

Fax: international +39.02 .50314881 .

E-mail: laura.vitellaro@unimi.it

Paper accepted on June 28, 2004.

European Journal of Histochemistry

2004; vol. 48 issue 4 (Oct-Dec):423-428 n optimal visualization of the vascular net-
work in the central nervous system is
required to investigate the anatomical features of the blood supply in either normal or pathological conditions, and is essential for morphometrical studies. In recent years, the determination of the microvessel density in different organs has proven to be a valuable tool to provide information on their metabolic activity and on the rate of neovascularization either during embryonic development or in pathological conditions, such as in response to ischemia or trauma and in tumorigenesis. The identification of blood vessels is usually carried out by a variety of affinity cytochemistry techniques, whose results, however, are conditioned by numerous technical restrictions. Although different vessel wall antigens have been successfully used as markers in human nervous tissue samples, their utilization across species may be hampered by the lack of available cross-reacting antibodies. Moreover, the visualization of the vascular bed may be difficult in tumor models, since many antigens that mark vessels in physiological conditions are not consistently expressed in tumoral tissues (Vermeulen et al., 1996); this shift in the antigenic properties reflects the influence of the microenvironment on the phenotype and function of the endothelial cells (Alessandri et al., 1999; Arosarena et al., 1994)

As a matter of fact, a reliable marker should a) allow a comprehensive identification of the vascular tree and be resistant to different conditions of tissue preparation (for instance, fixation and embedding), b) work in a range of species and experimental conditions, c) be compatible with other vascular and parenchymal markers.

In the present report we describe an easy and effective method to label normal and tumoral blood microvessels in the mouse, rat and guinea pig central nervous system that meets satisfactorily the above listed criteria. 


\section{Materials and Methods}

\section{Animals and tumor model}

Experiments in healthy animals were performed on two rats (Sprague-Dawley) at embryonic day 18 (E18), two rats at postnatal day 1 (P1), five adult rats, five adult mice $\left(\mathrm{C}_{57} \mathrm{BI}\right)$ and eight adult Hartley guinea pigs (Charles River, Calco, LC, Italy).

The University of Milan and the Istituto Nazionale Neurologico approved care and handling of animals in accordance with the International guidelines on the animal research of the European Community (86/609). All efforts were made to minimize animal suffering and to reduce the number of animals used.

Adult animals and $\mathrm{Pl}$ rats were anaesthetized with an intraperitoneal injection of chloral hydrate (4\%, $1 \mathrm{~mL} / 100 \mathrm{~g}$ body weight) and perfused transcardially with $1 \%$ paraformaldehyde in $0.1 \mathrm{M}$ phosphate buffer $\mathrm{pH} 7.2$ (PB), followed by $4 \%$ paraformaldehyde in the same buffer. The E18 embryos, obtained from an anaesthetized pregnant rat, were further anaesthetized with ether and perfused transcardially with the fixative, using a glass capillary. Brains and spinal cords were removed, postfixed in $4 \%$ paraformaldehyde in $\mathrm{PB}$ at $4^{\circ} \mathrm{C}$ for $12 \mathrm{~h}$ and either cut with a Vibratome in 50- $\mu \mathrm{m}$-thick sections or embedded in paraffin.

Four male Fisher 344 rats (Charles River) weighing about $180 \mathrm{~g}$ were used for intracerebral implantation of the $9 \mathrm{~L}$ gliosarcoma cell line (ATCC). Deeply anaesthetized animals were immobilized in a stereotactic frame (Bianchi et al., 1992), the skin was incized over the bregma and a small hole was drilled into the skull approximately $1 \mathrm{~mm}$ anterior, 4 $\mathrm{mm}$ lateral to the bregma. Ten $\mu \mathrm{l}$ of $9 \mathrm{~L}$ cell suspension (50,000 cells in PBS) were then injected at a depth of $4.5 \mathrm{~mm}$.

At the animal death, the brain was extracted and fixed by immersion in paraformaldehyde-lysine-periodate (PLP, McLean and Nakane, 1974) in PB (4 h at $4^{\circ} \mathrm{C}$ ), rinsed in $\mathrm{PB}$ for $12 \mathrm{~h}$ and embedded in paraffin.

\section{Lectin histochemistry}

Biotinylated lectin from Lycopersicon esculentum (bLEA, Sigma, St. Louis, MO), specific for N-acetylD-glucosamine and $\mathrm{N}$-acetyl-polylactosamine oligomers (Kawashima et al., 1990; Porter et al., 1990) was used.

Vibratome sections permeabilized with mild ethanol treatment (10\%-25\%-10\%, 10 min each) or paraffin-embedded dewaxed sections were treat- ed sequentially with a) $1 \% \mathrm{H}_{2} \mathrm{O}_{2}$ for 10 min to inactivate endogenous peroxidase, b) $0.01 \mathrm{M}$ phosphate buffered saline (PBS) containing $1 \%$ bovine serum albumin (PBSB) for $30 \mathrm{~min}$, and c) bLEA (10 $\mu \mathrm{g} / \mathrm{ml}$ ) diluted in PBSB for $2 \mathrm{hr}$.

Lectin binding was revealed with either a) standard ABC-peroxidase method ( $\mathrm{Hsu}$ et al., 1981) using the Vectastain $A B C$ kit (Vector Laboratories, Burlingame, CA, USA) and diaminobenzidine tetrahydrochloride (DAB) as a chromogen for light microscopy inspection, or b) streptavidinRhodamine RedX (Jackson Immunoresearch, West Grove, Pennsylvania) for fluorescence microscopy (in this case the preliminar treatment with $\mathrm{H}_{2} \mathrm{O}_{2}$ was omitted).

The specificity of lectin labeling was assessed by incubating control sections in either: a) PBSB in place of the lectin; $b$ ) bLEA preincubated for 30 min with $0.2 \mathrm{M} \mathrm{N}, \mathrm{N}^{\prime}, \mathrm{N}^{\prime}$-triacetyl-chitotriose (Sigma; Goldstein and Poretz, 1986).

\section{Immunocytochemistry}

Polyclonal rabbit antiserum directed against laminin purified from Engelbreth-Holm-Swarm murine tumor (EHS laminin, Sigma) and polyclonal goat antiserum to platelet-endothelial cell adhesion molecule-1 (PECAM-1, Santa Cruz Biotechnol., Santa Cruz, CA) were used respectively at 1:200 and 1:100 dilution. Free-floating vibratome sections or dewaxed sections were submitted to the same pretreatments listed for lectin histochemistry. After overnight incubation in the primary antibody at $4^{\circ} \mathrm{C}$, antigen-antibody reaction was revealed using an appropriate biotinylated secondary antibody (Vector, 1:200 for $75 \mathrm{~min}$ ) followed by the $A B C$ method. Prior to immunoreaction with anti-laminin serum, sections were submitted to digestion with $0.4 \%$ hyaluronidase from bovine testis (Sigma) in PBS, $30 \mathrm{~min}$ at $37^{\circ} \mathrm{C}$, for antigen unmasking (Folkvord et al., 1989).

For double labeling experiments, sections were sequentially incubated with bLEA and anti-laminin serum, followed by a mixture of Alexa 488-conjugated goat anti-rabbit IgG antibody and streptavidin-Rhodamine RedX (Jackson).

Single and double labeled sections prepared for fluorescence microscopy were examined under a TCS NT confocal laser scanning microscope (Leica Lasertecknik GmbH, Heidelberg, Germany), equipped with a 75-mW Kripton/Argon mixed gas laser, with a 10x objective lens (NA 0.3). Fluorochromes were 

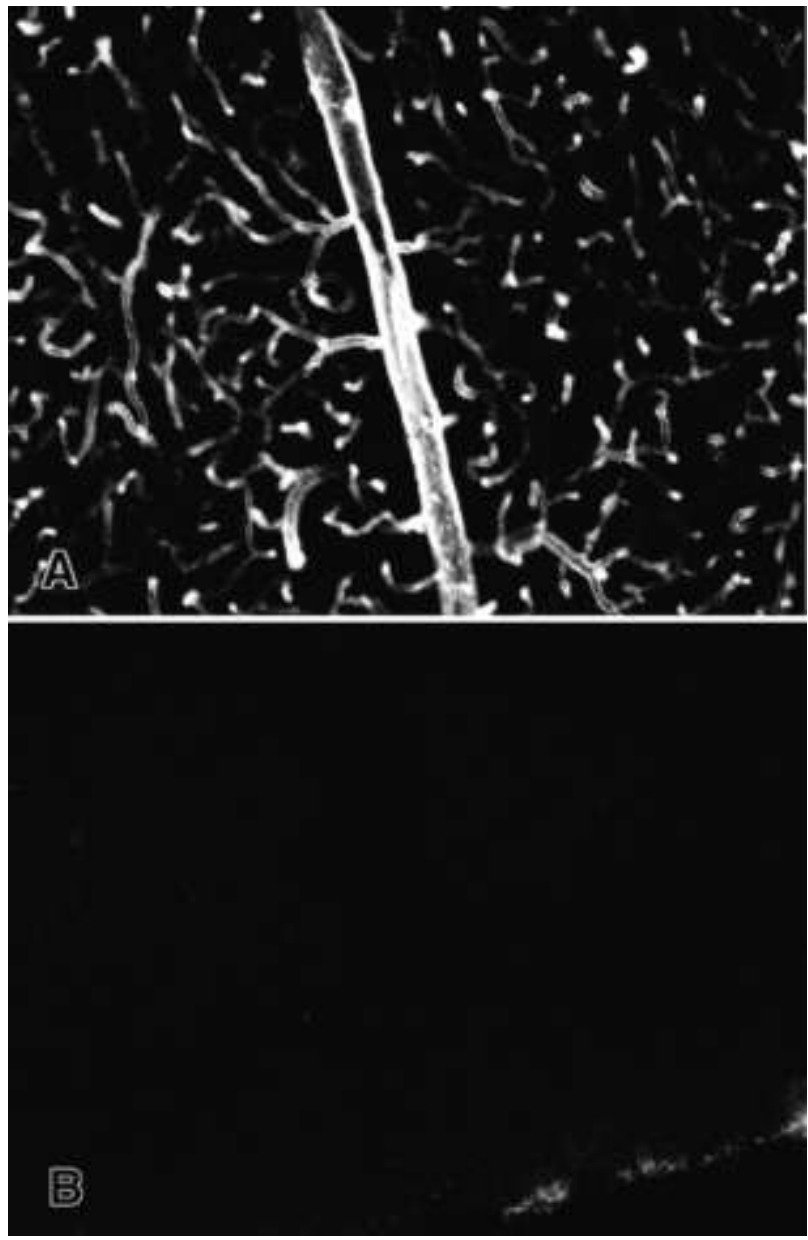

Figure 1. Analysis by confocal microscope of two adjacent vibratome sections of adult guinea pig cerebral cortex labeled respectively with biotinylated LEA $(A)$ and with biotinylated LEA preabsorbed with the inhibiting hapten sugar moiety (B). $\times 100$

excited respectively at 488 and $568 \mathrm{~nm}$, visualized with 530/30 nm band-pass and $590 \mathrm{~nm}$ long-pass filters, imaged separately and merged with Leica Power Scan software. Images, acquired with an aperture size of $102 \mu \mathrm{m}$ corresponding to an optical section of approximately $15 \mu \mathrm{m}$ in thickness, derived from the average of eight frames, were collected digitally as a matrix of $1024 \times 1024$ pixels and transferred to a graphics program (Adobe Photoshop 6.0). Control experiments showed that the levels of interchannel cross-talk were insignificant.

\section{Results}

The pattern of labeling obtained with bLEA was highly reproducible in all animal species, developmental ages and nervous system regions investigated. Moreover the distribution and the intensity of the staining were comparable in vibratome and

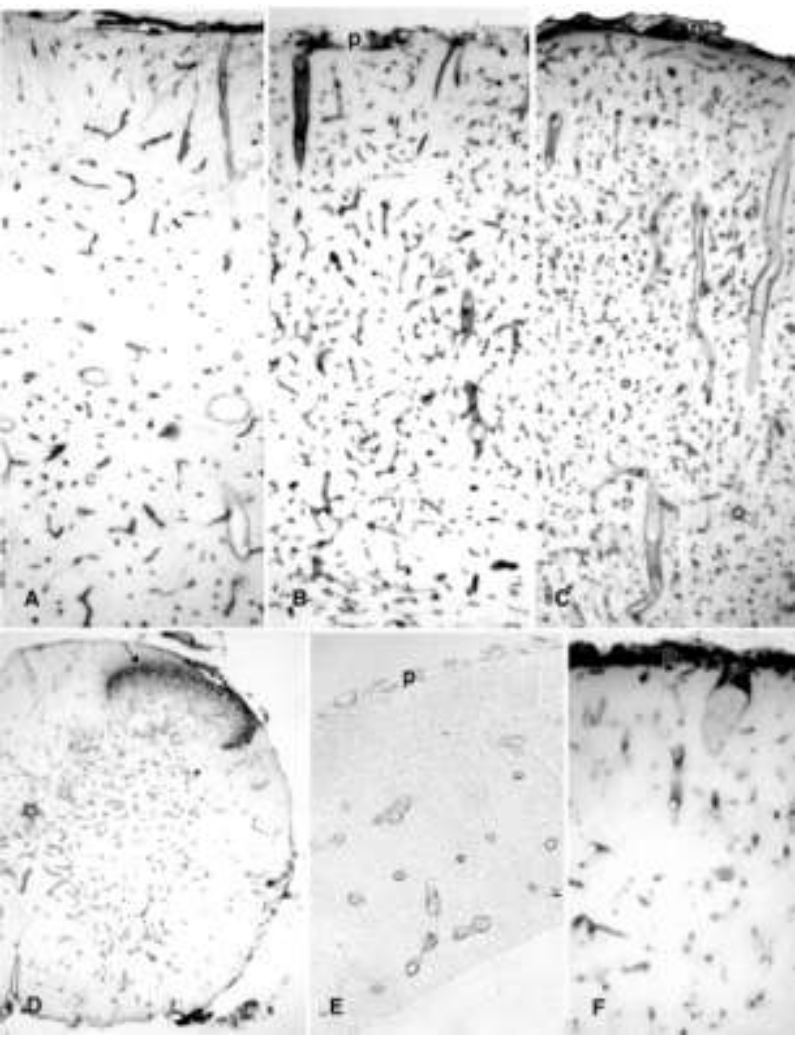

Figure 2. Light microscopy of coronal sections of adult mouse (A), rat (B) and guinea pig (C) parietal cerebral cortex, adult mouse spinal cord (D), rat cerebral cortex at E18 (E) and P1 (F). Binding of biotinylated LEA to the microvasculature was revealed with $A B C / D A B$ method. B-C, $F$ vibratome sections; $A$, $D, E$, paraffin sections. The arrow in $D$ points to lamina II of the dorsal horn; $p$, pia. A, B ×100; C, F ×80; D, ×70; E, ×225.

paraffin sections.

The specificity of LEA staining was demonstrated by the lack of labeling in control sections incubated in either a) PBSB in place of the lectin or b) bLEA preabsorbed with the appropriate hapten sugar moiety (Figure 1B).

In adult animals, LEA binding (Figures $1 \mathrm{~A}, 2 \mathrm{~A}-\mathrm{D}$ ) was localized exclusively to blood vessels in all regions of the central nervous system examined, except for the spinal cord where it specifically labeled also primary afferent fibers in laminae II and III of the dorsal horn (Figure 2D). LEA labeling was continuous along the wall of the vessels which presented a tube-like appearence (Figure $1 \mathrm{~A}, 2,3 \mathrm{~A}$ ). The examination of sections double-labeled for bLEA and EHS laminin showed that the entire vascular tree was stained in all samples examined, without significant differences in labeling intensity between vessels of different caliber (Figure 3 ). 

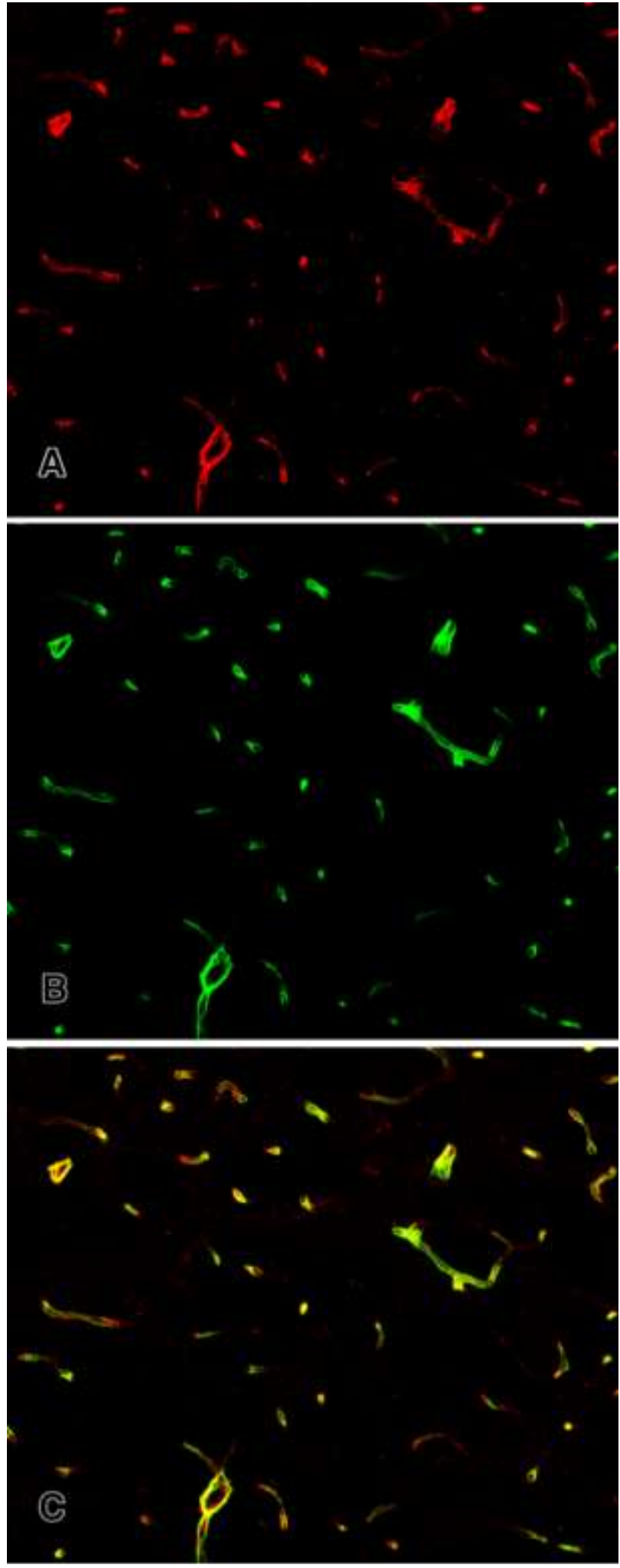

Figure 3. Analysis by confocal microscope of a paraffin section of adult guinea pig thalamus double labeled with biotinylated LEA (A) and serum anti-EHS laminin (B). C: merged images. ×180.

Moreover, at least in the rat, LEA appeared to label consistently the vascular cerebral network both at prenatal (E18) and perinatal developmental stages (Figures $2 \mathrm{E}, \mathrm{F}$ ).

In the tumor model, as in the surrounding normal brain parenchyma, the staining of the vascular network was very reproducible and consistent, with minimal background that enabled an easy identification of vascular profiles (Figures $4 A, B$ ).

LEA labeling efficiency of tumoral vessels appeared very high, especially when compared to that of two other frequently used vessel markers. Laminin immunoreactivity was intense in the vessels of the normal cerebral parenchyma (Figure 4D), whereas labeling of the tumoral vessels was very weak and incomplete (Figure $4 \mathrm{C}$ ). The same irregular staining was observed when tumor sections were immunostained with antibodies to PECAM-1 (not shown) that in addition produced a high background.

\section{Discussion}

Most lectins used as vascular markers in different organs and animal species selectively bind to glycoconjugates concentrated in the glycocalyx and in the basal membrane. Endothelial glycocalyx is a complex organization of integral and peripheral glycoproteins, glycolipids and proteoglycans bearing a variety of saccharide residues. These molecules are integrated in a complex filamentous meshwork that subserves multiple functions such as the regulation of microvessel permeability, blood flow, coagulation, fibrinolysis, angiogenesis and the interaction with plasma proteins and blood cells. The carbohydrate residues of the glycocalyx are exposed to vessel luminal surfaces and therefore are easily available to markers, thus making lectin labeling an effective and relatively simple tool to either image the morphology of the vascular tree or investigate the pattern of distribution of sugar residues in physiological and pathological conditions. The success of lectin staining depends on the selection of the appropriate markers, since the pattern of distribution of endothelial sugar moieties is developmentally (Pihush et al., 1994; Quondamatteo et al., 1997; Nico et al., 1998) and spatially regulated (Bankston et al., 1991) and it is, at least to a certain extent, species-specific (Russel and Dalion, 1988). For example, Ulex europaeus agglutinin, a lectin specific for non-reducing terminal alfa-fucosyl residues (Hindgaul et al., 1982; Pereira et al., 1978), is an efficient endothelial marker only in human tissues (Holthöfer et al., 1982). Conversely, optimal labeling of dog and chick 


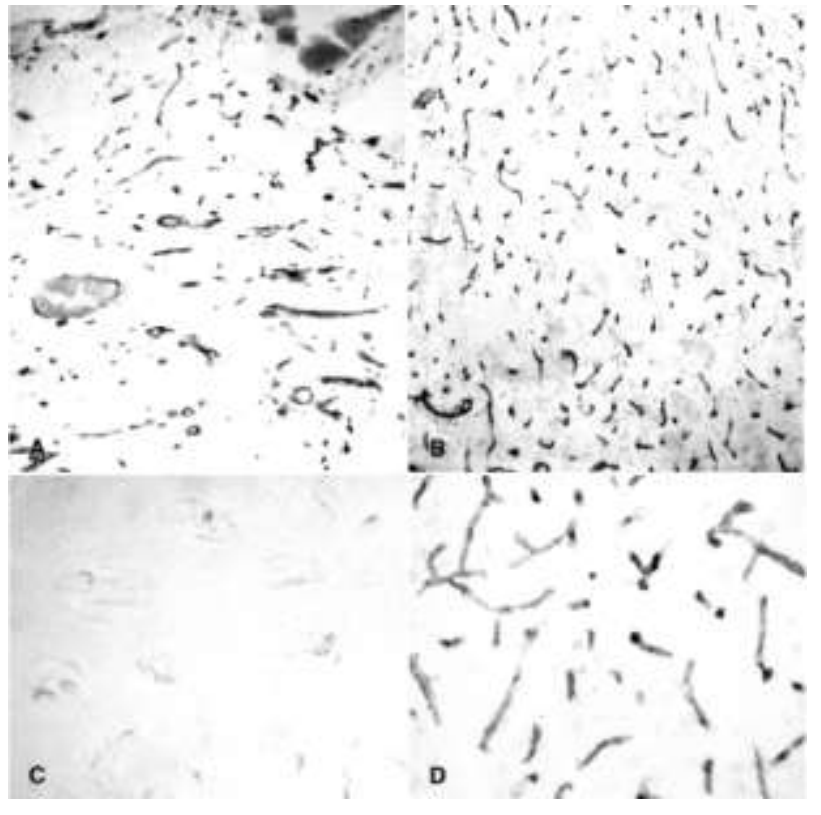

Figure 4. A-D Light microscopy of paraffin sections of $9 \mathrm{~L}$ gliosarcoma labelled with biotinylated LEA (A, B) and with antiserum to EHS laminin (C, D). ABC/DAB method. Microvasculature labeling is shown in $9 \mathrm{~L}$ gliosarcoma $(A, C)$ and in the surrounding normal brain tissue (B, D). A, B ×100; C, D ×260.

endothelium has been obtained with Arachis hypogaea (Kiatipattanasakul et al., 1998) and Lens culinaria lectins (Jilani et al., 2003), respectively.

Lectin histochemistry has been frequently used to visualize the morphology of vascular networks in a variety of organs, either on tissue sections (Porter et al., 1990; Hansen-Smith et al., 1988; Nanka et al., 2001; Beltrão et al., 2003; Jilani et al., 2003; Cebasek et al., 2004) or using intravascular perfusion (Thurston et al., 1998, 1999; Murphy et al., 1999; Debbage et al., 2001; Jilani et al., 2003). However, lectins have been only rarely used to delineate the vascular tree in the central nervous system (Porter et al., 1990), although their affinity to brain endothelium has been extensively characterized ( Nag 1985a, b; Vorbrodt, 1986; Vorbrodt et al., 1986; Alroy et al., 1987; Fatehi et al., 1987; Porter et al., 1990; Debbage et al., 1996; Gerhart et al., 1998). In the present paper, we extend previous observations (Porter et al., 1990) showing that LEA staining allows the comprehensive visualization of the vascular network of brain and spinal cord in three mammalian species widely used as models in the studies of the central nervous system. This lectin is specific for $(\mathrm{GICNAC}) n(\mathrm{n}>3)$ and poly-N-acetyllactosamine residues (Nachbar et al., 1980; Zeng et al., 1998) and it has been previously shown to label the endothelium in several non nervous organs of different mammal species (Porter et al., 1990; Bankston et al., 1991; Augustin et al. 1995; Thurston et al. 1996, 1998; Murphy et al., 1999; Debbage et al., 2001). The presence of binding sites for LEA in the endothelia of all the nervous organs, animal species and developmental stages examined in the present study likely reflects the important recognition functions played by polylactosaminoglycans in cell membranes (Feizi, 1985). Our findings are in line with previous observations (Debbage, 1996) showing that the oligosaccharide sets that characterize the glycosylation pattern of receptors and adhesion molecules and include polylactosamines are highly conserved in brain endothelia.

An optimal visualization of the vascular bed is particularly important to characterize the processes of angiogenesis and vascular remodeling taking place in pathological conditions, like tumors or inflammatory diseases. However, the identification of newly formed blood vessels, especially in tumors, is frequently hampered by the altered expression of the vessel wall antigens commonly used as markers (Vermeulen et al., 1996). In the present investigation, we have compared, using a gliosarcoma model, the staining efficiency of LEA with that of two antibodies recognizing respectively the endothelial adhesion molecule PECAM-1 and laminin, a glycoprotein of basal membranes. Our findings showed that only LEA stained consistently all tumoral vessels and indicate that, at variance with sialylated oligosaccharides (Debbage et al., 1994), the binding sites for this lectin are not lost in tumoral tissue.

LEA staining offers a few distinct advantages over other vascular markers: a) it produces only minimal parenchymal staining, thus allowing an easier identification of the vascular profiles, which is an essential requirement to perform morphometric analysis of the vasculature; $b$ ) its binding properties are preserved in paraffin embedded nervous tissue, enabling the analysis of archivial samples; c) it can be combined with other labeling techniques.

In conclusion, the complex of our observations indicate that LEA may represent an effective and versatile endothelial marker for the study of the vasculature of the central nervous system in different animal species and experimental conditions.

\section{Acknowledgements}

This work was supported by a grant from the Italian Health Ministry (RF 00177). The authors are grateful to Dr. M. de Curtis (Istituto Neurologico C. Besta, Milano) for the critical reading of the manuscript. 


\section{References}

Alessandri G, Chirivì RG, Fiorentini S, Dossi R, Bonardelli S, Giulini $S M$, et al. Phenotypic and functional characteristics of tumorderived microvascular endothelial cells. Clin Exp Metastasis 1999; 17:655-62.

Alroy J, Goya V, Skutelsky E. Lectin histochemistry of mammalian endothelium. Histochemistry 1987;86:603-7.

Arosarena 0, Guerin C, Brem H, Laterra J. Endothelial differentiation in intracerebral and subcutaneous experimental gliomas. Brain Res 1994;640:98-104.

Augustin HG, Braun K, Telemenakis I, Modlich U, Kuhn W. Ovarian angiogenesis. Phenotypic characterization of endothelial cells in a physiological model of blood vessel growth and regression. Am J Pathol 1995; 147:339-51.

Bankston PW, Porter GA, Milici AJ, Palade GE. Differential and specific labeling of epithelial and vascular endothelial cells of the rat lung by Lycopersicon esculentum and Griffonia simplicifolia I lectins. Eur J Cell Biol 1991;54:187-95.

Beltrão EIC, Medeiros PL, Rodrigues OG, Figueredo-Silva J, Valença M M, Coelho LCBB, et al. Parkia pendula lectin as histochemistry marker for meningothelial tumour. Eur J Histochem 2003;47:139-42.

Bianchi $M$, Sacerdote $P$, Ricciardi-Castagnoli $P$, Mantegazza $P$, Panerai AE. Central effects of tumor necrosis factor and interleukin-1 on nociceptive thresholds and spontaneous locomotor activity. Neurosci Lett 1992;148:74-84.

Cebasek V, Kubínová L, Ribaric S, Erzen I. A novel staining method for quantification and 3D visualisation of capillaries and muscle fibres. Eur J Histochem 2004;48:151-8.

Debbage PL, Pihusch R, Lang S, Bise HJ. Altered carbohydrates at the endothelial cell membranes in gliomas. Clin Neuropathol 1994; 13:241.

Debbage PL. A systematic histochemical investigation in mammals of the dense glycocalyx glycosylations common to all cells bordering the interstitial fluid compartment of the brain. Acta Histochem 1996; 98:9-28.

Debbage $P L$, Sölder E, Seidl S, Hutzler P, Hugl B, Öfner D, et al. Intravital lectin perfusion analysis of vascular permeability in human micro- and macro-blood vessels. Histochem Cell Biol 2001;116:349-59.

Fatehi MI, Gerhart DZ, Myers TG, Drewes LR. Characterization of the blood-brain glycoconjugate receptors of 14 lectins in canine brain, cultured endothelial cells, and blotted membrane proteins. Brain Res 1987;415:30-9.

Feizi T. Demonstration by monoclonal antibodies that carbohydrate structures of glycoproteins and glycolipids are oncodevelopmental antigens. Nature 1985;314:53-7.

Folkvord J M, Viders D, Coleman-Smith A, Clark RAF. Optimization of immunohistochemical techniques to detect extracellular matrix proteins in fixed skin specimens. J Histochem Cytochem 1989;37:105-13.

Gerhart DZ, Enerson BE, Zhdankina OY, Lein RL, Drewes LR. Expression of the monocarboxylate transporter MCT2 by rat brain glia. Glia 1998;22:272-81.

Goldstein IT, Poretz RD. Isolation and chemical properties of lectins. In The Lectins: Properties, functions and applications in biology and medicine (Liener IE, Sharon N, Goldstein IT, Editors). Academic Press, New York 1986;33-247.

Hansen-Smith FM, Watson L, Goldstein I. Griffonia simplicifolia I: fluorescent tracer for microcirculatory vessels in nonperfused thin muscles and sectioned muscle. Microvasc Res 1988;36:199-215.

Hindsgaul 0, Norberg T, Le Pendu J, Lemieux RU. Synthesis of type 2 human blood group antigenic determinants. The $H, X$, and $Y$ haptens and variations of the type 2 determinant as probes for the combining site of the lectin I of Ulex europaeus. Carbohydr Res 1982; 109:109-42.

Holthöfer $\mathrm{H}$, Virtanen A, Kariniemi M, Hormia E, Linder A, Miettinen A. Ulex europaeus I lectin as a marker for vascular endothelium in human tissues. Lab Invest 1982;47:60-6.
Hsu SM, Raine L, Fanger $\mathrm{H}$. Use of avidin-biotin-peroxidase complex $(A B C)$ in immunoperoxidase techniques: a comparison between $A B C$ and unlabeled antibody (PAP) procedures. J Histochem Cytochem 1981;29:557-80.

Jilani SM, Murphy TJ, Thai SN M, Eichmann A, Alva JA, Iruela-Arispe $M L$. Selective binding of lectins to embryonic chicken vasculature. J Histochem Cytochem 2003;51:597-604.

Kawashima H, Sueyoshi S, Li H, Yamamoto K, Osawa T. Carbohydrate binding specificities of several poly- $\mathrm{N}$-acetyllactosamine-binding lectins. Glycoconj J 1990;7:323-34.

Kiatipattanasakul W, Nakayama H, Nakamura S, Doi K. Lectin histochemistry in the aged dog brain. Acta Neurophatol 1998;95:261-8.

McLean IW, Nakane PK. Periodate-lysine-paraformaldehyde fixative. A new fixation for immunoelectron microscopy. J Histochem Cytochem 1974;22:1077-83.

Murphy TJ, Thurston G, Ezaki T, McDonald DM. Endothelial cell heterogeneity in venules of mouse airways induced by polarized inflammatory stimulus. Am J Pathol 1999;155:93-103.

Nachbar MS, Oppenheim JD, Thomas JO. Lectins in the U.S. diet. Isolation and characterization of a lectin from the tomato (Lycopersicon esculentum). J Biol Chem 1980;255:2056-61.

Nag S. Ultrastructural localization of lectin receptors on cerebral endothelium. Acta Neuropathol 1985;66:105-10.

Nag S. Ultrastructural localization of monosaccharide residues on cerebral endothelium. Lab Invest 1985;52:553-8.

Nanka 0, Peumans WJ, Van Damm, EJM, Pfüller U, Valase P, Halata $Z$, et al. Lectin histochemistry of vascular endothelium in chick and quail musculature. Anat Embryol 2001;204:407-11.

Nico B, Quondamatteo F, Ribatti D, Bertossi M, Russo G, Herken R, et al. Ultrastructural localization of lectin binding sites in the developing brain microvasculature. Anat Embryol 1998;197:305-15.

Pereira MEA, Kisailus EC, Gruezo, F, Kabat EA. Immunochemical studies on the combining site of blood group $\mathrm{H}$-specific lectin I from Ulex europaeus seeds. Arch Biochem Biophys 1978;185:108-15.

Pihush R, Debbage PL, Bise HJ, Lange W. Carbohydrate modulation at the intracerebral endothelial cell membrane during ontogenesis and neo-angiogenesis in man. Clin Neuropathol 1994;13:263.

Porter GA, Palade GE, Milici AJ. Differential binding of the lectins Griffonia simplicifolia I and Lycopersicon esculentum to microvascular endothelium: organ specific localization and partial glycoprotein characterization. Eur J Cell Biol 1990;51:85-95.

Quondamatteo F, Got W, Lubben U, Herken R. Changes in lectin binding sites during early human liver development. Histochem Cell Biol 1997; 107:223-8.

Roussel F, Dalion J. Lectins as markers of endothelial cells: comparative study between human and animal cells. Lab Anim 1988; 22: 135-40.

Thurston G, Baluk P, Hirata A, McDonald DM. Permeability-related changes revealed at endothelial cell border in inflamed venules by lectin binding. Am J Physiol 1996;271:H2547-H62.

Thurston G, Murphy TJ, Baluk P, Lindsey JR, McDonald DM. Angiogenesis in mice with chronic airway inflammation. Am J Pathol 1998;153:1099-112.

Thurston G, Suri C, Smith K, McClain J, Sato TN, Yancopoulos GD, et al. Leakage-resistant blood vessels in mice transgenically overexpressing angiopoietin-1. Science 1999;286:2511-4.

Vermeulen PB, Gasparini G, Fox SB, Toi M, Martin L, McCulloch P, et al. Quantification of angiogenesis in solid human tumors: an international consensus on the methodology and criteria of evaluation. Eur J Cancer 1996;32A:2474-84.

Vorbrodt AW. Changes in the distribution of endothelial surface glycoconjugates associated with altered permeability of brain micro-blood vessels. Acta Neuropathol 1986;70:103-11.

Vorbrodt AW, Dobrogowska DH, Lossinsky AS, Wisniewski HM. Ultrastructural localization of lectin receptors on the luminal and abluminal aspects of brain micro-blood vessels. J Histochem Cytochem 1986;34:251-61.

Zeng X, Murata T, Kawagishi H, Usui T, Kobayashi K. Analysis of specific interactions of synthetic glycopolypeptides carrying $\mathrm{N}$-acetyllactosamine and related compounds with lectins. Carbohydr Res $1998 ; 312: 209-17$. 